\title{
CORRIGENDUM
}

\section{Characterization of X-ray-generated floral mutants carrying deletions at the $S$-locus of distylous Turnera subulata}

JDJ Labonne, F Tamari and JS Shore

Heredity (2010) 105, 244; doi:10.1038/hdy.2010.83

Correction to: Heredity (2010) 105, 235-243; doi:10.1038/ hdy.2010.39; published online 14 April 2010

The authors have discovered an error that they would like to correct. Figure 3, Characterization of 12 S-locus mutants, shows two markers (RP81E18 and P9SP1) at distances of $<0.5$ and $0.5 \mathrm{cM}$, respectively. The actual distance for marker RP81E18 is $<0.05 \mathrm{cM}$, and that for marker P9SP1 is $0.05 \mathrm{cM}$, as correctly indicated in the text.

The authors apologize for this error. 